Kansas State University Libraries

New Prairie Press

\title{
BINOMIAL VARIATION IN THE SEX COMPOSITION OF PIG FAMILIES
}

Thomas Kirchoff

D. F. Cox

Follow this and additional works at: https://newprairiepress.org/agstatconference

Part of the Agriculture Commons, and the Applied Statistics Commons

\section{(c) $(1) \ominus$}

This work is licensed under a Creative Commons Attribution-Noncommercial-No Derivative Works 4.0 License.

\section{Recommended Citation}

Kirchoff, Thomas and Cox, D. F. (1993). "BINOMIAL VARIATION IN THE SEX COMPOSITION OF PIG

FAMILIES," Conference on Applied Statistics in Agriculture. https://doi.org/10.4148/2475-7772.1387

This is brought to you for free and open access by the Conferences at New Prairie Press. It has been accepted for inclusion in Conference on Applied Statistics in Agriculture by an authorized administrator of New Prairie Press. For more information, please contact cads@k-state.edu. 


\title{
Binomial Variation in the Sex Composition of Pig Families ${ }^{1}$
}

\author{
Thomas Kirchoff and D.F. Cox \\ Iowa State University \\ Ames, Iowa 50011
}

\begin{abstract}
Given the known mechanisms for sex determination, the number of males in families of pigs should follow a binomial distribution. A report of deviations from binomial expectation prompted an investigation of 33,176 pig records from two breeds collected on a single farm. Two methods of assessing the agreement with the binomial distribution found no evidence of significant lack of fit.
\end{abstract}

\section{Introduction}

The chromosomal basis of sex determination predicts a binomial distribution of the composition of families with the probability of being male equal to 0.5 at conception. A report by Brooks et al. [1] gave data indicating significant departure from the binomial expectations in pig families at birth. They indicated too few unisexual or near unisexual families, a situation they termed as sub-binomial. Data on the sex of 33,176 pigs from two breeds born over 14 seasons on a single farm allowed the examination of the distribution of the composition of pig families and the determination of the adequacy of the binomial distribution in describing the results.

\section{$2 \quad$ Background}

Given the known sex determination mechanisms, an equal number of females and males should occur at conception, and the composition of families should follow a binomial distribution with the probability of a male, or a female, equal to 0.5. Data on the sex of fertilized ova will always remain scarce; therefore, the first practical time to count comes at birth. In pigs, this occurs approximately 113 days after conception. Almost never do the sexes appear equally frequent at birth in mammals. A common assumption ascribes this result to differential prenatal mortality that follows conception, but little actual data supporting this idea exists.

One way to examine the goodness of fit of number of males in families of pigs to the expectations based on a binomial distribution uses the chi-squared statistic. This method tests for departures from expectations within each family size using the overall probability of an individual being male provided by the data. Robertson [2] gave another approach to the analysis of heterogenity in the binomial distribution.

\footnotetext{
${ }^{1}$ Journal Paper No. J-15432 of the Iowa Agriculture and Home Economics Experiment Station, Ames, Iowa. Project No. 0101.
} 


\section{Results and Discussion}

The breeds of pigs used in this work had slightly different proportions of males at birth as the following shows:

\begin{tabular}{lrrrr} 
& \multicolumn{2}{c}{ Sex } & & Proportion \\
Breed & Male & Female & Total & Male \\
Duroc & 8.382 & 8417 & 16799 & 0.499 \\
Hampshire & 8397 & 7980 & 16377 & 0.513 \\
\cline { 2 - 3 } Total & 16779 & 16397 & 33176 &
\end{tabular}

Chi-square, adjusted for continuity, testing for equal proportion male in these two breeds equalled 6.238 . The probability of a greater value of the chi-square $=0.013$.

Using the estimates of the proportion male from each breed, we generated the expected number of families with $0,1,2, \cdots \mathrm{k}$ males in each family size in each breed and used chi-square to test the goodness of fit. We combined data from adjacent classes until the expected number in a class equalled at least one. The degrees of freedom used equalled one less than the number of classes used in each family size. We did not attempt any adjustment in degrees of freedom for using the overall data to estimate the proportion male.

As an example, in the 226 Duroc families of size 10 at birth, the following observed, expected, and chi-square occurred:

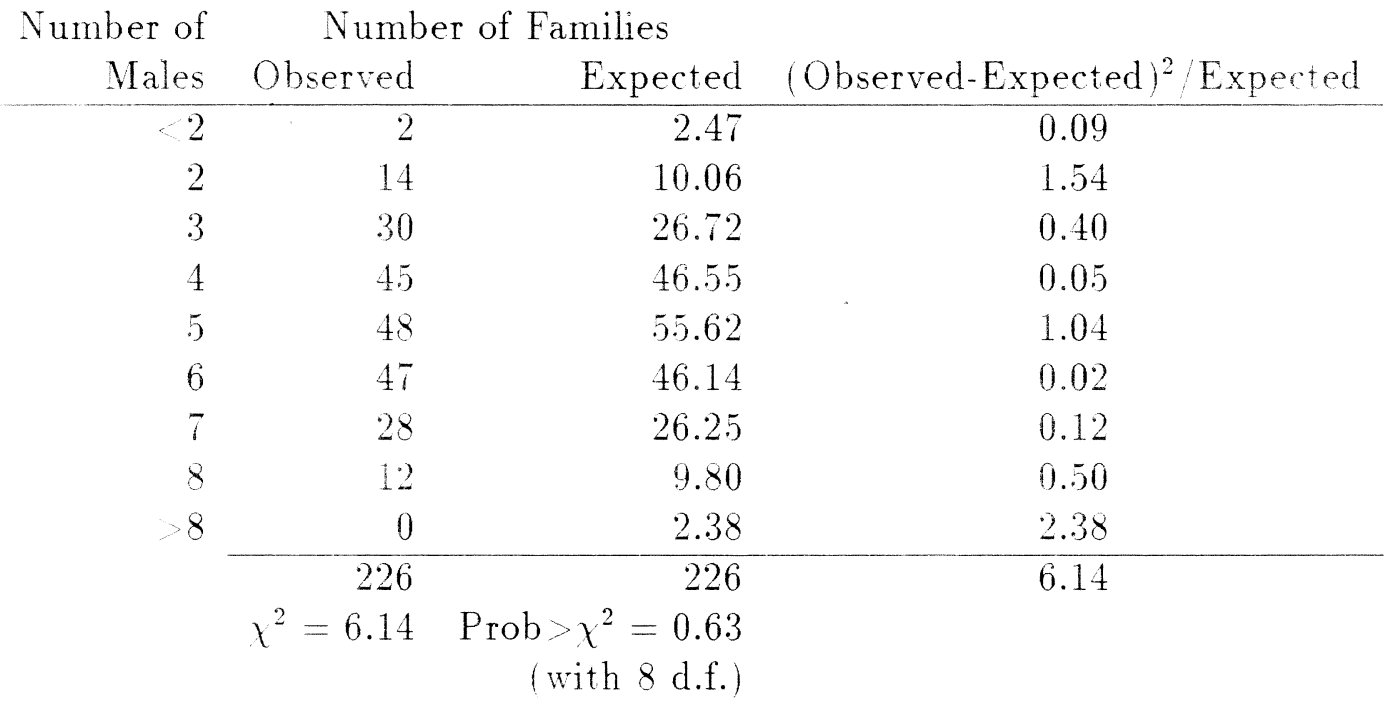

Table 1 provides a summary of such tests for each family size in each breed. The table lists the probability of larger values for the 35 independent chi-squared statistics calculated. If the number of males in pig families follows a binomial distribution, approximately 4 of the p-values would fall below 0.10 . The count of such values in Table 1 equalled 6 . The tests provided no evidence to reject the binomial expectations.

A more unified and flexible approach to examining heterogeniety in the binomial distribution of the number males comes from a paper by Robertson [2]. For each 
family, the value of $\mathrm{K}$ is computed:

$$
K=\frac{1}{2}\left[\frac{f(f-1)}{q^{2}}-\frac{m(m-1)}{p^{2}}-\frac{2 f m}{p q}\right]
$$

where

$$
\begin{aligned}
& \mathrm{f}=\text { number of females in the family } \\
& \mathrm{m}=\text { number of males in the family } \\
& \mathrm{n}=\mathrm{f}+\mathrm{m} \\
& \mathrm{p}=\text { proportion of males in the distribution as } \\
& \\
& \mathrm{q}=1-\mathrm{p} \text { whole }
\end{aligned}
$$

For a sample of $\mathrm{N}$ families, each of size $\mathrm{n}$, take

$$
\begin{gathered}
\sum I=\frac{N n(n-1)}{2 p^{2} q^{2}} \\
\sum K=\sum_{i=1}^{N} K_{i}
\end{gathered}
$$

Robertson showed that the $\frac{\sum K}{\sum I}$ is distributed normally with sampling variance $\frac{1}{\sum I}$ and that $\frac{\sum \sum K}{\sum \sum I}$ is also distributed normally with sampling variance $\frac{1}{\sum \sum I}$ where the summation may be carried out over groups of families of different size and with different values of $p$. Hence we can test the entire sample (both breeds of pigs) as well as each breed individually for evidence of sub-binomial dispersion.

Compared with the chi-square goodness of fit test, Robertson's test is computationally more efficient with this data and the statistical significance of the results are more easily interpreted. Both methods make the same assumption, i.e. that the observations represent a random sample.

The results of Robertson's test are displayed in Table 2. Again, no evidence of deviation from ordinary binomial dispersion was found. 
Table 1: Summary of chi-squared tests for goodness of fit to a binomial distribution of the number of males in each family size of each breed.

\begin{tabular}{|c|c|c|c|c|c|c|}
\hline \multirow{3}{*}{$\begin{array}{l}\text { Family } \\
\text { Size }\end{array}$} & \multicolumn{2}{|c|}{ Duroc } & \multicolumn{4}{|c|}{ Hampshire } \\
\hline & No. of & Chi- & & No. of & Chi- & \\
\hline & Families & Square & $\mathrm{P}$ & Families & Square & $\mathrm{P}$ \\
\hline 1 & & & & 5 & 1.96 & .16 \\
\hline 2 & 17 & 7.52 & .02 & 17 & 5.10 & .08 \\
\hline 3 & 13 & 2.34 & .50 & 25 & 0.52 & .91 \\
\hline 4 & 20 & .55 & .97 & 38 & 4.65 & .32 \\
\hline 5 & 40 & 13.35 & .02 & 63 & 10.45 & .06 \\
\hline 6 & 55 & 1.15 & .89 & 94 & 6.15 & .41 \\
\hline 7 & 77 & 7.02 & .22 & 121 & 2.06 & .91 \\
\hline 8 & 128 & 4.70 & .58 & 148 & 8.43 & .21 \\
\hline 9 & 165 & 6.61 & .47 & 250 & 2.24 & .95 \\
\hline 10 & 226 & 6.14 & .63 & 214 & 11.47 & .18 \\
\hline 11 & 227 & 3.75 & .93 & 248 & 4.35 & .89 \\
\hline 12 & 207 & 10.10 & .26 & 182 & 7.56 & .48 \\
\hline 13 & 196 & 12.17 & .20 & 149 & 2.90 & .97 \\
\hline 14 & 106 & 5.85 & .66 & 84 & 15.93 & .04 \\
\hline 15 & 65 & 11.85 & .22 & 35 & 18.34 & .01 \\
\hline 16 & 28 & 4.29 & .83 & 12 & 9.07 & .17 \\
\hline 17 & 11 & 4.08 & .54 & 3 & 0.53 & .47 \\
\hline 18 & 7 & 0.79 & .94 & & & \\
\hline 19 & 3 & 0.35 & .35 & & & \\
\hline
\end{tabular}

Table 2: Results of Robertson's Test

No. of

\begin{tabular}{lccc} 
Source & families & Test statistic, $z$ & $\mathrm{P}>\mathrm{z} \mid$ \\
\hline Duroc & 1593 & 0.63 & 0.5 \\
Hampshire & 1690 & -0.18 & 0.9 \\
Both breeds & 3283 & 0.34 & 0.7 \\
\hline
\end{tabular}




\section{Summary}

Two different methods were used to test whether the data on the sex of 33,176 pigs followed the binomial distribution. Neither the chi-square tests nor Robertson's test gave evidence of deviation from ordinary binomial dispersion.

\section{References}

[1] Brooks, R.J., James, W.H., Gray, E. (1991). Modelling sub-binomial variation in the frequency of sex combinations in litters of pigs. Biometrics 47, 403-415.

[2] Robertson, A. (1951). The analysis of heterogeneity in the binomial distribution. Annals of Eugenics (London) 16, 1-15. 